\title{
BMJ Open Consumption trends and prescription patterns of opioids from 2011 to 2016: a survey in a Chinese city
}

\author{
Xiao Liu, ${ }^{1}$ Can Luo, ${ }^{2}$ Huizhen Dai, ${ }^{3}$ Wentong Fang ${ }^{2}$
}

To cite: Liu X, Luo C, Dai H, et al. Consumption trends and prescription patterns of opioids from 2011 to 2016: a survey in a Chinese city. BMJ Open 2019;9:e021923. doi:10.1136/ bmjopen-2018-021923

- Prepublication history and additional material for this paper are available online. To view these files, please visit the journal online (http://dx.doi. org/10.1136/bmjopen-2018021923).

Received 28 January 2018 Revised 6 November 2018 Accepted 7 January 2019

Check for updates

(C) Author(s) (or their employer(s)) 2019. Re-use permitted under CC BY-NC. No commercial re-use. See rights and permissions. Published by BMJ.

${ }^{1}$ Department of Pharmacy, Qinghai provincial Peoples Hospital, Xining, Qinaghai, China ${ }^{2}$ Department of Pharmacy, First Affiliated Hospital of Nanjing Medical University, Nanjing, Jiangsu, China

${ }^{3}$ Department of Pharmacy, Jiangsu Medicine Information Institute, Nanjing, China

Correspondence to Dr Wentong Fang;

fangwentong@jsph.org.cn

\section{ABSTRACT}

Objective Opioid consumption in China has been very less and has varied widely since 1995 . The representatively high level of consumption in Mainland China has never been reported. Our aim was to describe the consumption trends and prescription patterns of opioids in Nanjing, a highly developed city of Mainland China, and compare the results with selected worldwide regions.

Methods Application data of opioids in 2011-2016 were extracted from the Jiangsu Medicine Information Institute. Six opioids were included. Consumption was expressed in terms of defined daily doses (DDDs), morphine equivalents (MEs) and expenditure. The correlation between

consumption of opioids and gross domestic product (GDP), Human Development Index (HDI) and cancer incidence was analysed by Pearson's correlation test.

Results DDDs, expenditure and MEs of opioids were, respectively, 256.04, \$599.24 and $13.07 \mathrm{~g}$ in 2011, and increased to $361.27, \$ 1041.79$ and $18.09 \mathrm{~g}$ in 2016 . DDDs in Nanjing were 2.80-fold that in Mainland China, 1.42fold that in East and South-East Asia, but only equivalent to $8.89 \%$ of the worldwide average level. From 2011 to 2016, the consumption had a linear correlation with GDP, $\mathrm{HDI}$ and cancer incidence $(p<0.05)$. However, DDDs varied greatly in countries with similar GDP or HDI. Within 45 Asian countries, the GDP only contributed to $10.47 \%$ of change in DDDs, while the HDI contributed to $20.32 \%$. Consumption of non-intravenous opioids or strong opioids always comprised majority of the total consumption. The opioids prescribed predominantly were fentanyl, oxycodone and morphine. Fentanyl and oxycodone account for most of the increase in consumption.

Conclusion 0pioid consumption has increased $>40 \%$ from 2011 to 2016, with consumption of fentanyl and oxycodone accounting for most of that increase. The consumption in Nanjing was higher than the average Chinese level, but lower than the global average. An increase in pain control services might be needed, but this need should be highly regulated.

\section{INTRODUCTION}

An opioid is a type of substance that acts on opioid receptors to produce morphinelike effects and is indicated for the relief of mild-to-severe pain. ${ }^{1} 2$ Opioids are effective for the treatment of acute pain (such as pain following surgery) and cancer pain, and have been identified by WHO

\section{Strengths and limitations of this study}

This is the first study investigating the consumption trends and prescription patterns of opioids in Nanjing, China, that has seen a huge increase in opioid consumption from 2011 to 2016.

- One of the strengths of this study is the cross-country comparison of opioid consumption between Nanjing and selected worldwide regions, reflecting the relatively low consumption in Nanjing as compared with the whole world.

- Another strength is Pearson's correlation test between consumption and influencing factors, which revealed that gross domestic product, Human Development Index and cancer incidence account for some changes in opioid use, but are not determinant factors.

- Our study provides valuable evidence to the Chinese government and health organisations for laying emphasis on the control of pain and expansion of pain services.

- The limitation of our data is that the term 'consumption' is used for the quantity of opioid prescribed but does not relate to how much is actually administered.

as 'indispensable for the relief of pain and suffering', so that their availability 'must be' ensured. ${ }^{34}$ However, consumption of opioids varies widely between countries. ${ }^{5-8}$ During 2011-2013 the annual global consumption, expressed as defined daily doses per million people per day (DDDs PMPPD), was $3027 .^{7}$ The average annual consumption in USA and Canada was up to 43879 and 22 941, respectively, ${ }^{7}$ while that in Asian countries was relatively low. Within Asia, the high level was 4664 in Israel, and the low level was less than 10 in Laos, Cambodia, Bangladesh, Yemen and so on. ${ }^{7}$ The annual consumption in China was 96 , which was the moderate level of Asia, but much lower than the worldwide average level. $^{78}$

Consumption of opioids varies widely between cities because of the large diversity within China. The average DDDs in Macao 
and Hong Kong, two cities in China, were, respectively, 221 and 175 in $2011-2013,{ }^{7}$ while the average DDD in Taiwan was 560 in $2007 . .^{9}$ Their health service systems and cultural traditions are different from most cities in the Chinese mainland. The representatively high level of consumption in Mainland China has not been reported. Nanjing, a city in Eastern Mainland China, with a population of $>8000000$, area of $6587 \mathrm{~km}^{2}$ and gross domestic product (GDP) ranking eleventh among 338 cities in $2016,{ }^{10}$ is the political, economic and cultural centre of Southern China. The health service systems and cultural traditions of Nanjing are similar to most other cities in the Chinese mainland. Hence Nanjing has been chosen to represent the highly developed parts of China.

According to the China Food and Drug Administration (CFDA) criterion, $^{11}$ opioids as prescription medicines are legally sold in hospitals only in order to avoid abuse. There are only 34 hospitals authorised by CFDA in Nanjing. Pain and addiction are assessed by doctors before prescription. Opioid abuse or misuse of opioid is supervised by CFDA. The abuse/utilisation rate of opioids prescribed in hospitals in this area was $0.01 \%-1.00 \%$ in 2016. ${ }^{12}$ Opioids prescribed in hospitals are considered to be used for legal medical purposes. In this study, Nanjing has been chosen as a representative of the highly developed parts of China, to investigate consumption trends and prescription patterns of opioids from 2011 to 2016, and compare the results with selected regions worldwide.

\section{METHODS}

\section{Data sources}

Data on opioids were provided by the Jiangsu Medical Information Institute. According to the CFDA criterion, ${ }^{11}$ every opioid prescription in Nanjing should be reported by the hospital to this institute. Each hospital has a designated reporter, usually a pharmacist, who is responsible for registering the consumption of drugs. The reporter collects information for each opioid including dosage form, package dose, manufacturer, price, monthly expenditure and monthly consumption (in terms of grams). The designated reporter reports data on a monthly basis. A specific network system has also been designed for data uploading, summarising, analysing and storage. The designated reporter imports data to the network system, and the network system automatically sends data to the Jiangsu Medicine Information Institute. A designated statistical officer collects, summarises and analyses data from different hospitals.

Eight kinds of opioids are used in Nanjing city; they are morphine, fentanyl, oxycodone, codeine, hydromorphone, pethidine, buprenorphine and methadone. Dextropropoxyphene, ketobemidone, tilidine and trimeperidine are not available in China. Methadone and buprenorphine were excluded because their use for pain relief cannot be distinguished from their predominant use for treatment of dependence on illicit opioid. ${ }^{7}$ Therefore, morphine, fentanyl, oxycodone, codeine, hydromorphone and pethidine were included and analysed in our study.

The institute reported the consumption of opioid in terms of grams and prices. We estimated them in terms of DDDs, morphine equivalents (MEs) and expenditures. The DDDs of opioids in other regions and countries were reported by Berterame et al. ${ }^{7}$ GDP and Human Development Index (HDI) in other countries were retrieved from the World Bank ${ }^{13}$ and the Human Development Report. ${ }^{14}$ The population, GDP, HDI and cancer incidence in Nanjing were obtained from the statistical yearbook of the Nanjing Statistics Bureau. ${ }^{10}$

\section{Statistical analysis}

DDD is a statistical unit defined by the WHO Collaborating Centre (WHOCC) for Drug Statistics Methodology. ${ }^{15}$ In our study, DDDs were shown as the values PMPPD and calculated with the following formula:

DDDs $=\left(\sum\right.$ (Total dose used $\left.) / \mathrm{DDD}\right) / 365 /$ population

$\mathrm{ME}$ is another measuring unit for the consumption recommended by International Association for Hospice and Palliative Care (IAHPC). ${ }^{16} 17$ ME ratios are recommended by WHOCC for Drug Statistics Methodology. ${ }^{18}$ In our study, MEs were shown as the values PMPPD and calculated using the following formula:

MEs $=\left(\sum(\right.$ Total dose used $) *($ ME ratio $\left.)\right) / 365 /$ population

The expenditure of opioids was recorded in Renminbi (RMB) and then converted to US dollars. Expenditure was shown as expenditure PMPPD and calculated using the following formula:

Expenditure $=($ expenditure $) /$ dollar exchange rate/365/population

GDP was shown as GDP PMPPD and was calculated using the following formula:

GDP $=($ total GDP $) / 365 /$ population

The correlation between consumption of opioids and GDP, HDI and cancer incidence was analysed by applying Pearson's correlation test and linear regression analysis using SPSS V.21 (IBM Corporation, Armonk, New York, USA). A value of $\mathrm{p}<0.05$ was considered to show a statistically significant linear correlation.

\section{Patient and public involvement}

Patients were not involved because this study included no human participants.

\section{RESULT}

\section{Opioid consumption had an increasing tendency}

The consumption of opioids in Nanjing city increased year by year from 2011 to 2016 . DDD was 256.04 in 2011 ; it increased by $7.13 \%$ per year and reached 361.27 in 2016 (figure 1A). The average DDD was 302.24 during 20112016. The expenditure was $\$ 599.24$ in 2011 , increased by $11.70 \%$ per year and reached $\$ 1041.79$ in 2016 (figure 1B). The average expenditure was $\$ 781.99$ during 2011-2016. ME was $13.07 \mathrm{~g}$ in 2011, increased by $6.72 \%$ 


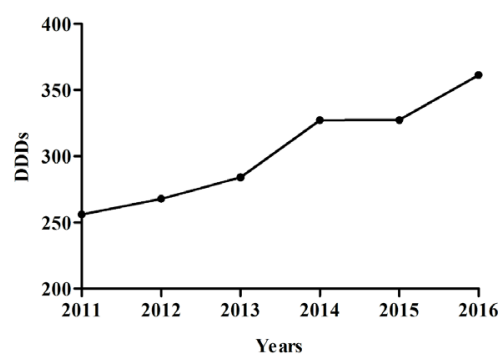

(A)

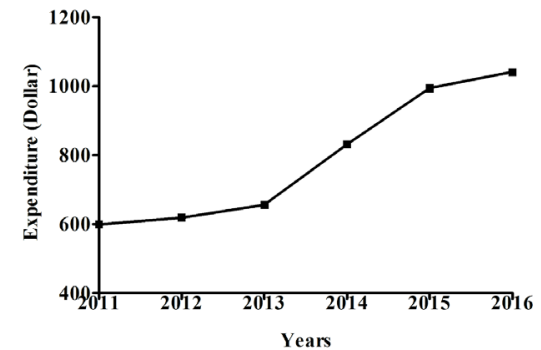

(B)

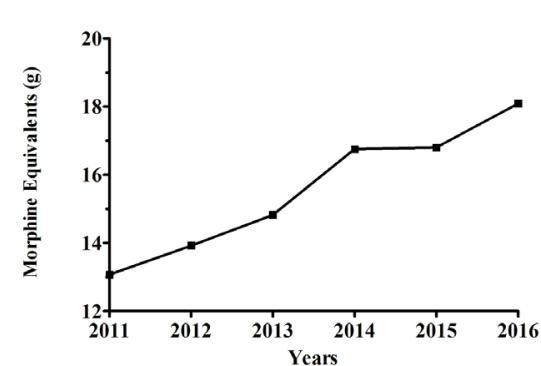

(C)

Figure 1 Consumption of opioids in Nanjing from 2011 to 2016. (A) DDDs of opioids. (B) Expenditure on opioids. (C) MEs of opioids. DDD, defined daily dose; ME, morphine equivalent.

per year and reached $18.09 \mathrm{~g}$ in 2016 (figure 1C). The average ME was $15.58 \mathrm{~g}$ during 2011-2016.

\section{Consumption in Nanjing is relatively low in the world}

Within China, the annual average DDD in Nanjing was 269, which is about 2.80-fold of that in the Chinese mainland (online supplementary table S1) and slightly higher than that in Macau (221) and Hong Kong (175) during 2011-2013. ${ }^{7}$ Nanjing is a city in the East and South-East of Asia, so we compared the DDD in Nanjing with that of the other countries in this area. During 20112013, DDD in Nanjing was 1.42-fold of the average value in East and South-East Asia, but much lower than the DDDs in South Korea, Japan, Singapore (online supplementary table S1).

In order to reveal the level of opioid consumption of Nanjing in the whole world, we compared the DDDs of Nanjing with the average value of the whole world and every main region. DDD in Nanjing was only $8.89 \%$ of the worldwide average level, $0.86 \%$ of North America, $2.89 \%$ of West and Central Europe, $2.94 \%$ of Oceania and $24.45 \%$ of South-East Europe. It was close to the average level in South America and West Asia, but higher than the average level in East and South-East Asia, East Europe, Central America, Africa and South Asia (online supplementary table S2).

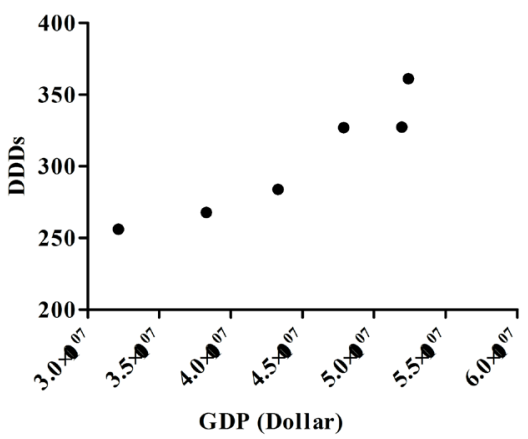

(A)

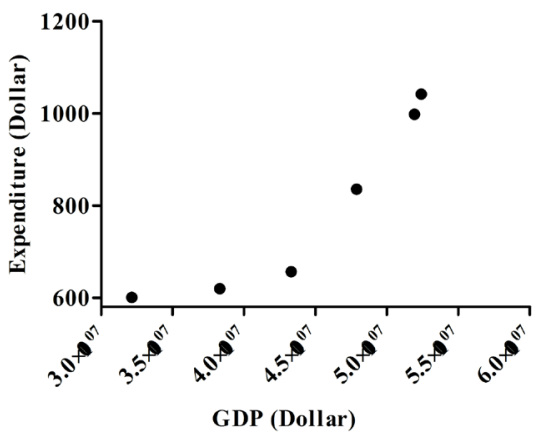

(C)

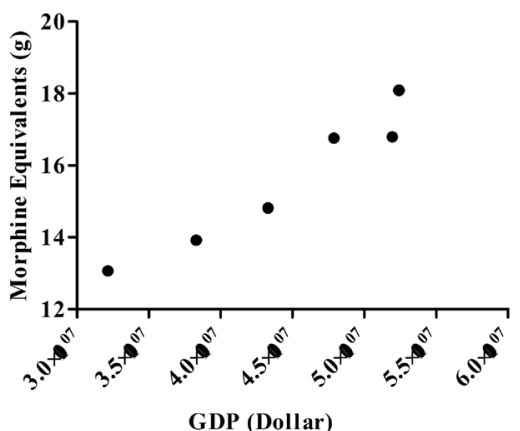

(B)

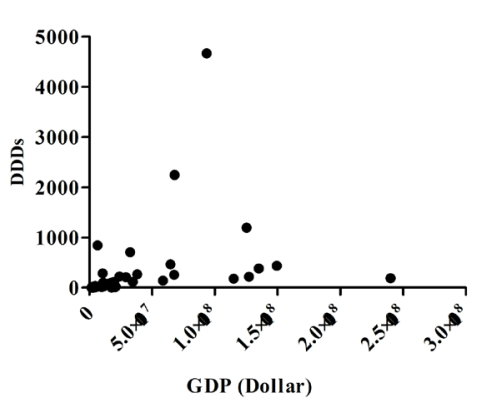

(D)

Figure 2 Correlation of GDP and consumption of opioids in Nanjing from 2011 to 2016. (A) Correlation between GDP and DDDs of opioids in Nanjing from 2011 to 2016. (B) Correlation between GDP and expenditure on opioids in Nanjing from 2011 to 2016. (C) Correlation between GDP and MEs of opioids in Nanjing from 2011 to 2016. (D) Linear regression analysis of GDP and DDDs in 45 Asian countries. DDD, defined daily dose; GDP, gross domestic product; ME, morphine equivalent. 
Table 1 Opioid consumption in regions with similar GDP

\begin{tabular}{llc}
\hline Regions & $\begin{array}{l}\text { Average GDP } \\
(\mathbf{2 0 1 1 - 2 0 1 3 )} \text { (USD ) }\end{array}$ & $\begin{array}{l}\text { Average DDDs } \\
\text { (2011-2013) }\end{array}$ \\
\hline Worldwide & 28808219 & 3027 \\
Panama & 29035616 & 309 \\
Kazakhstan & 35863014 & 120 \\
\hline Hungary & 36928767 & 3984 \\
Seychelles & 37197260 & 184 \\
Poland & 37268493 & 1916 \\
Croatia & 37764384 & 2733 \\
Nanjing & 38049315 & 269 \\
Latvia & 38879452 & 1122 \\
Lithuania & 40550685 & 1237 \\
Chile & 41643836 & 747 \\
\hline
\end{tabular}

DDDs are shown as the values per million people per day. GDPs are shown as the GDP per million people per day. $\mathrm{DDD}$, defined daily dose; GDP, gross domestic product.

\section{Factors influencing the consumption of opioid}

Previous studies have reported that GDP and HDI are important determinants of opioid consumption. ${ }^{7}$ GDP has increased at an annual rate of $10.26 \%$ from 2011 to 2016 (figure 2), so correlation analysis was carried out. GDP had a linear correlation with DDDs $\left(\mathrm{R}^{2}=0.94, \mathrm{p}=0.005\right)$ (figure 2A), MEs $\left(\mathrm{R}^{2}=0.97, \mathrm{p}=0.002\right.$ ) (figure $2 \mathrm{~B}$ ) and expenditure $\left(\mathrm{R}^{2}=0.92, \mathrm{p}=0.008\right.$ ) (figure $2 \mathrm{C}$ ). However, DDDs of opioids varied greatly in countries with similar
GDPs (\$28-\$42 million) (table 1). DDDs in Nanjing were significantly lower than in some European countries, such as Hungary, Poland, Croatia and Latvia, but higher than in Kazakhstan (Asia) and Seychelles (Africa) (table 1). GDP only contributed to $10.47 \%$ of change in DDDs in a linear regression model of 45 Asian countries $\left(\mathrm{R}^{2}=0.1047, \mathrm{p}=0.0301\right)$ (figure 2D).

HDI increased by $1.64 \%$ per year. HDI was also correlated with DDDs of $\left(\mathrm{R}^{2}=0.90, \mathrm{p}=0.014\right)$ (figure $3 \mathrm{~A}$ ), MEs of $\left(R^{2}=0.94, p=0.006\right)$ (figure $3 B$ ) and expenditures $\left(\mathrm{R}^{2}=0.86, \mathrm{p}=0.028\right)$ (figure 3C) on opioids from 2011 to 2016. In countries with similar HDI (0.79-0.83), DDDs of opioids varied greatly. DDD in Nanjing was remarkably higher than in some European countries such as Hungary, Croatia, Latvia, Portugal and Montenegro, but mildly lower than in some Asian countries such as Bahrain and Kuwait (table 2). GDP only contributed to $20.32 \%$ of change in DDDs in a linear regression model of 45 Asian countries $\left(\mathrm{R}^{2}=0.1686, \mathrm{p}=0.0019\right)$ (figure $3 \mathrm{D}$ ).

Cancer incidence increased by $6.28 \%$ per year from 2011 to 2016 (figure 4). Cancer incidence was correlated with DDDs of $\left(\mathrm{R}^{2}=0.98, \mathrm{p}=0.001\right.$ ) (figure $4 \mathrm{~A}$ ), MEs of $\left(\mathrm{R}^{2}=0.98, \mathrm{p}=0.001\right)$ (figure $4 \mathrm{~B}$ ) and expenditures on $\left(\mathrm{R}^{2}=0.97, \mathrm{p}=0.002\right)$ (figure $4 \mathrm{C}$ ) opioids from 2011 to 2016.

\section{Prescription pattern of opioids}

Consumption of non-intravenous opioids accounted for majority of the total consumption from 2011 to 2016 . The DDDs of non-intravenous opioids increased by $6.81 \%$ per

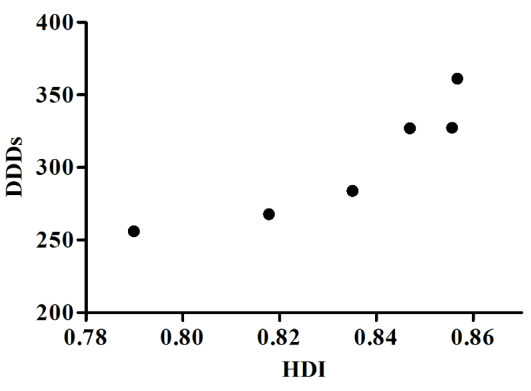

(A)

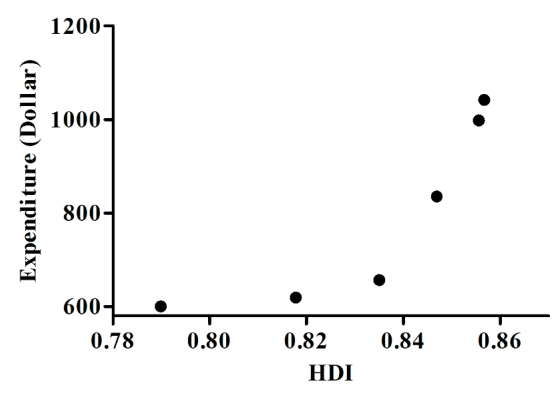

(C)

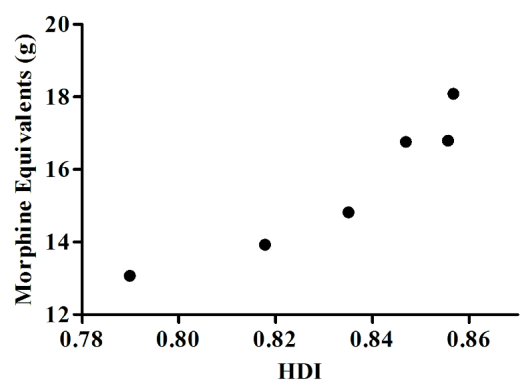

(B)

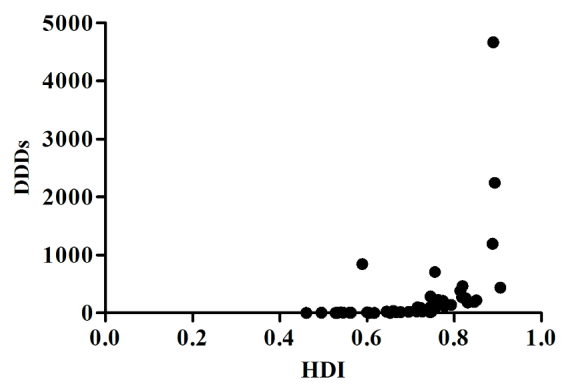

(D)

Figure 3 Correlation of HDI and consumption in Nanjing from 2011 to 2016. (A) Correlation between HDI and DDDs of opioids in Nanjing from 2011 to 2016. (B) Correlation between HDI and expenditure on opioids in Nanjing from 2011 to 2016 . (C) Correlation between HDI and MEs of opioids in Nanjing from 2011 to 2016. (D) Linear regression analysis of HDI and DDDs in 45 Asian countries. DDD, defined daily dose; HDI, Human Development Index; ME, morphine equivalent. 
Table 2 Opioid consumption in regions with similar HDI

\begin{tabular}{llc}
\hline Regions & $\begin{array}{l}\text { Average HDI } \\
(\mathbf{2 0 1 1 - 2 0 1 3 )}\end{array}$ & $\begin{array}{c}\text { Average DDDs } \\
(\mathbf{2 0 1 1 - 2 0 1 3 )}\end{array}$ \\
\hline Portugal & 0.827 & 2302 \\
\hline Chile & 0.826 & 747 \\
\hline Hungary & 0.824 & 3984 \\
Bahrain & 0.819 & 465 \\
Nanjing & 0.818 & 269 \\
\hline Latvia & 0.814 & 1122 \\
\hline Croatia & 0.816 & 2733 \\
\hline Kuwait & 0.814 & 383 \\
\hline Montenegro & 0.799 & 1498 \\
\hline Belarus & 0.795 & 300 \\
\hline
\end{tabular}

DDDs are shown as values per million people per day.

DDD, defined daily dose; HDI, Human Development Index.

year (figure 5A), while their expenditure increased by $7.34 \%$ per year (figure $5 \mathrm{~B}$ ). Consumption of intravenous opioids accounted for a minor part of the total consumption from 2011 to 2016. The DDDs of and expenditure on intravenous opioids, respectively, increased by $9.33 \%$ (figure $5 \mathrm{~A}$ ) and $27.18 \%$ per year (figure $5 \mathrm{~B}$ ).

Strong opioids took more than $99 \%$ of the total consumption. The annual growth rates of DDDs and expenditures were $7.18 \%$ (figure $6 \mathrm{~A}$ ) and $11.69 \%$, respectively (figure 6B). The proportion of weak opioids was always low, though it increased steadily.

Consumption of fentanyl, which was the most widely applied type of opioid, accounted for more than $50 \%$ of the total consumption during 2011-2016. DDDs of, MEs of and expenditures on fentanyl increased from 2011 to 2014, but decreased in 2015 (figures 7A-C). Fentanyl accounted for most of the increase in consumption during 2011-2014. In our study, the DDDs of transdermal fentanyl were 157.38, 175.70, 192.16, 214.89, 194.90 and 205.35, and the DDDs of fentanyl injection were 23.46, $25.81,29.79,34.13,36.21$ and 36.95 from 2011 to 2016, respectively. The DDDs of transdermal fentanyl were higher than those of fentanyl injection during our study period.
Consumption of oxycodone, which accounted for more than $10 \%$ of the total consumption, decreased from 2011 to 2013, but increased from 2013 to 2016. Oxycodone accounted for most of the increase in consumption during 2011-2014 (figures 7A-C). Consumption of morphine changed little and accounted for more than $10 \%$ of the total consumption in 2011-2016 (figure 7). Consumption of other opioids such as codeine, pethidine and hydromorphone was low in 2011-2016 (figures 7A-C).

\section{DISCUSSION}

Consumption of opioids in China has been very low and has varied widely since $1995 .^{7819}$ Because of the unbalanced development in the different regions in China, Nanjing was chosen as a representative of the highly developed part of China. In our study, the DDD in Nanjing was higher than that in Macau and Hong Kong, and was about 2.80-fold that of the Chinese average level during 2011-2013, reflecting the high level of opioid consumption in China. Two major findings of the present study are the continuous increase in the consumption of opioids in Nanjing in the recent past and the change in the consumption pattern.

Though opioid consumption in Nanjing increased gradually reflecting the continuous progress in pain relief, the level is still low compared with the selected worldwide regions. Within East and South-East Asia, the DDD in Nanjing was much lower than that of South Korea, Japan and Singapore. Around the world, the DDD in Nanjing was much lower than the average levels in North America, West and Central Europe, Oceania and South-East Europe. Previous studies have demonstrated the low opioid consumption in China. ${ }^{78}$ In our study, the DDD in Nanjing, which reflected the high consumption level in China, was relatively low in comparison to other regions worldwide.

Previous studies have reported that GDP and HDI are important determinants of opioid consumption. ${ }^{7}$ So a correlation analysis was carried out. As expected, the consumption in Nanjing correlated with its GDP and HDI. The GDP and HDI in Nanjing are higher than the average

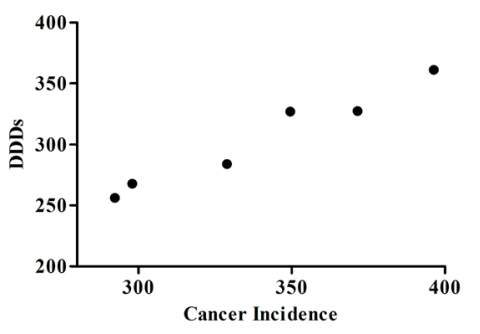

(A)

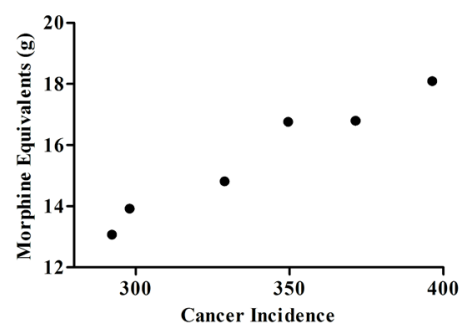

(B)

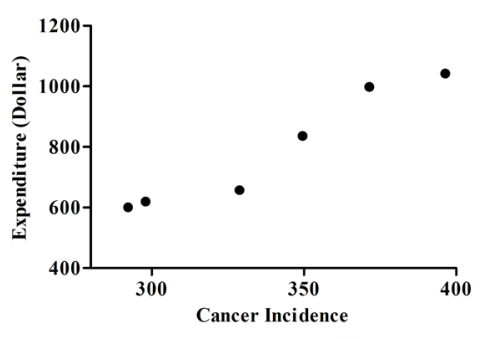

(C)

Figure 4 Correlation between cancer incidence and consumption in Nanjing from 2011 to 2016. (A) Correlation between cancer incidence and DDDs of opioids. (B). Correlation between cancer incidence and expenditure on opioids. (C) Correlation between cancer incidence and MEs of opioids. DDD, defined daily dose; ME, morphine equivalent. 


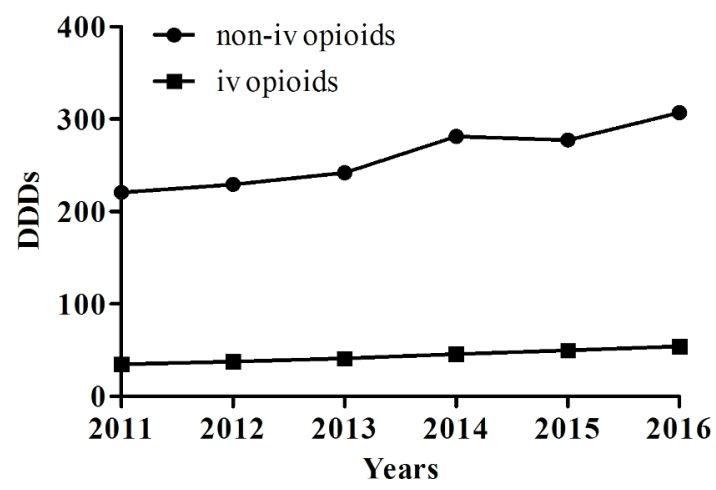

(A)

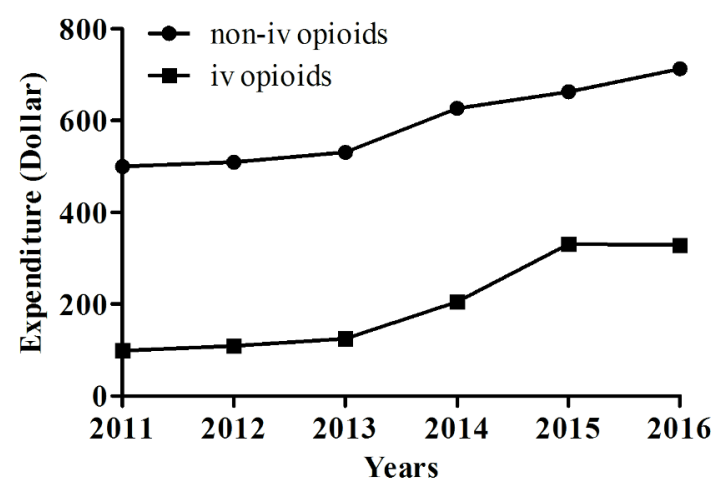

(B)

Figure 5 Consumption of intravenous (iv) and non-intravenous opioids in Nanjing from 2011 to 2016. (A) DDDs of intravenous or non-intravenous opioids. (B) Expenditure on intravenous or non-intravenous opioids. DDD, defined daily dose.

Chinese levels, which might explain the high consumption of opioids. However, countries with similar GDP or HDI have significantly different opioid consumptions. In 45 Asian countries, GDP contributed to only $10.47 \%$ change in DDD, while HDI contributed to $20.32 \%$. So GDP and HDI do not seem to play a crucial role in the diversity between regions and countries; this has also been demonstrated in our previous study. ${ }^{8}$

Opioids are commonly prescribed for pain. ${ }^{20}$ Chronic non-cancer pain can be due to various diseases, and it is difficult to determine its incidence. Hence, we only analysed the relationship between opioid consumption and cancer pain. Data on cancer prevalence in Nanjing are not available, so cancer incidence was substituted for cancer prevalence. Opioid consumption was correlated with cancer incidence from 2011 to 2015 in Nanjing, suggesting that cancer incidence accounted for some changes in opioid use.

Other impediments also influenced opioid application, such as reimbursement policies and prescription regulations, availability of pain services, and so on. ${ }^{921-23}$ In China, all types of opioids have been covered by insurance, but the reimbursement ratio varies with the different types of insurance. Reimbursement policies and prescription regulations of opioids did not change in Nanjing from 2011 to 2016, and their effect on opioid consumption was small. Expansion of pain services could be other possible contributors to this increase. The National Health and Family Planning Commission of the People's Republic of China launched the 'Good Pain Management Programme (GPM programme)' across the country since 2011. ${ }^{24}$ Twenty-nine hospitals in Nanjing have enrolled in this programme since 2012. ${ }^{25}$ The GPM programme has proved to improve the pain management of patients with cancer. ${ }^{26}$

WHO's cancer pain ladder for adults and the National Comprehensive Cancer Network (NCCN) guidelines highlight non-invasive administration of opioids. ${ }^{27} 28$ Therefore, a major part of the total consumption was of non-intravenous opioids, and this consumption tended to increase in Nanjing from 2011 to 2016.

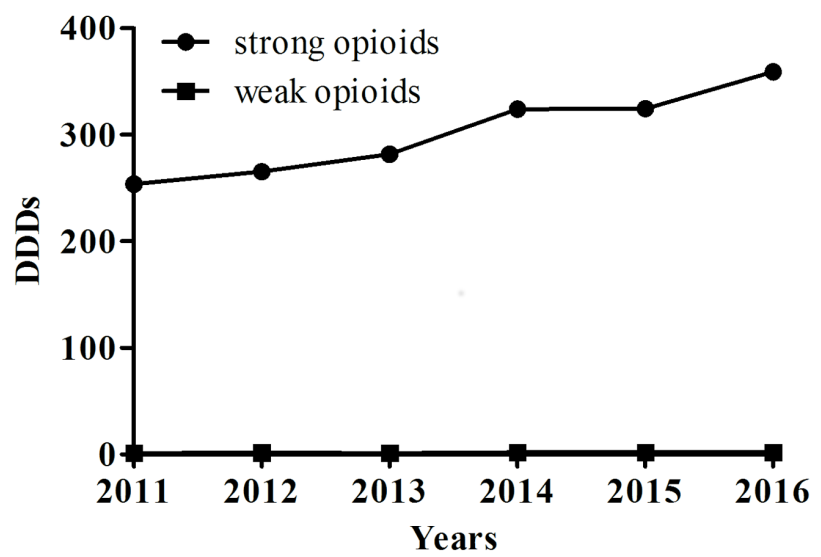

(A)

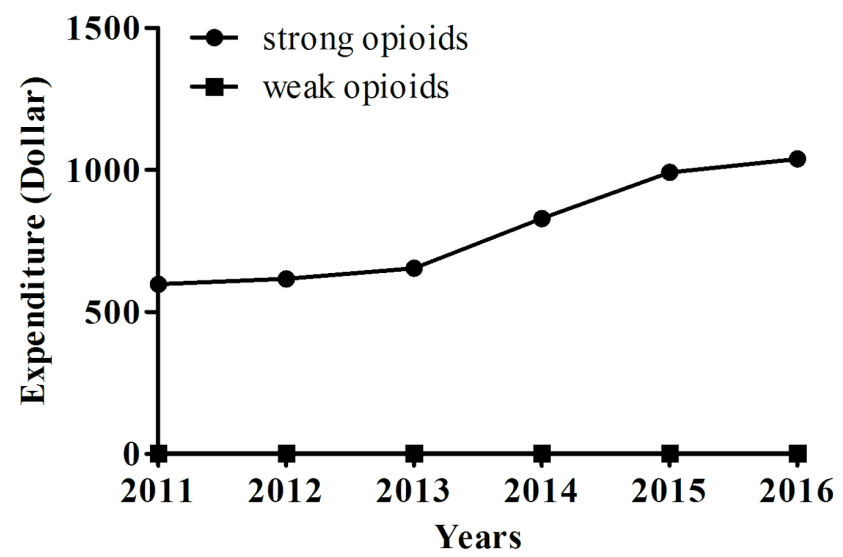

(B)

Figure 6 Consumption of strong and weak opioids in Nanjing from 2011 to 2016. (A) DDDs of strong and weak opioids. (B) Expenditures on strong and weak opioids. DDD, defined daily dose. 


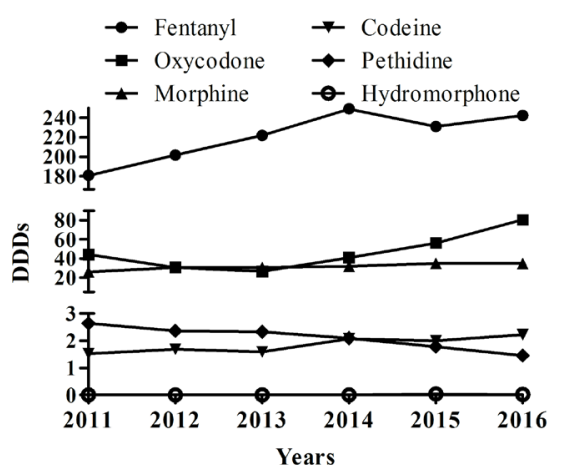

(A)

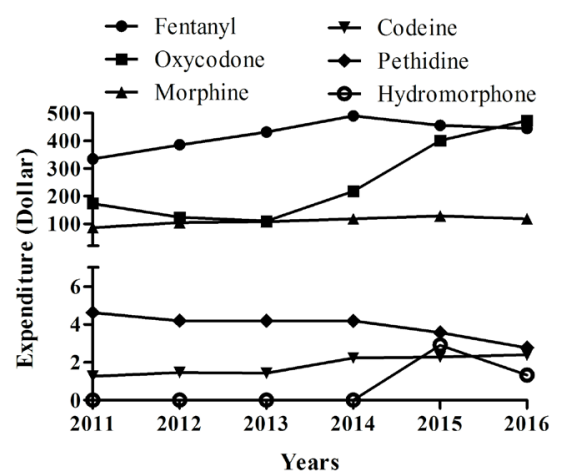

(B)

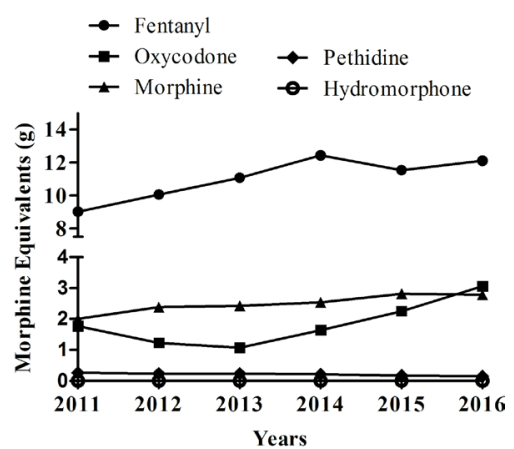

(C)

Figure 7 Consumption of main opioids in Nanjing from 2011 to 2016. (A) DDDs of main opioids. (B) Expenditures on main opioids. (C) MEs of main opioids. DDD, defined daily dose; ME, morphine equivalent.

The WHO three-step 'ladder' had recommended weak opioids for patients with moderate pain since $1986 .{ }^{27}$ Recent research has revealed that passing directly from step 1 to step 3 of the WHO analgesic ladder is more effective than the traditional three-step strategy for mild-to-moderate chronic cancer pain. ${ }^{28} 29$ Nowadays, the European Association for Palliative Care guidelines recommend a small dose of strong opioid instead of weak opioid in patients with refractory moderate pain. ${ }^{30}$ The NCCN Adult Cancer Pain Guideline (V.1.2015) recommends opioid for all levels of pain. ${ }^{31}$ This could explain the overwhelming use of strong opioids in Nanjing during 2011-2016.

Consumption of morphine remains stable, while consumption of fentanyl, oxycodone and methadone has increased in many countries; ${ }^{32-34}$ this suggests changes in the prescription pattern of opioids for pain management. In Nanjing transdermal fentanyl has come into use since 1999, and controlled-release oxycodone since 2004. The consumption of fentanyl might have been overestimated in our study. The DDD value for fentanyl used in this study was $0.6 \mathrm{mg}$, which was recommended by WHO and International Narcotics Control Board, but the daily dose is usually $1.2-2.4 \mathrm{mg} /$ day in practice. In order to compare the consumption with other regions and countries, we chose $0.6 \mathrm{mg}$ as the DDD value of fentanyl.

In our study, the DDD of transdermal fentanyl was much higher than that of fentanyl injection during the study period. Transdermal patch is the mostly used species, and accounted for most of the increasing of consumption in 2011-2014. We retrospectively analysed the application of fentanyl in 2016 in our hospital. Fentanyl is mainly used for the treatment of cancer pain, but is also used sometimes for relief from acute postoperative pain, rheumatoid arthritis, osteoporosis and postherpetic neuralgia.

Transdermal fentanyl has some advantages in the management of cancer pain, such as very long halflife $^{35}$ and much fewer opioid-related gastrointestinal side effects, such as nausea, vomiting and constipation. ${ }^{36-38}$ Fentanyl has been reported to be used in the treatment of patients with chronic non-cancer pain such as rheumatoid arthritis, osteoporosis and postherpetic neuralgia. ${ }^{39} 40$
The consumption of oxycodone has increased since 2013, and accounts for most of the increase in consumption during 2015-2016. Oxycodone is mostly used in the controlled-release form, which has a lower rate of constipation, nausea and vomiting than controlled-release morphine. ${ }^{41}{ }^{42}$ A previous study has reported that the rescue analgesic dose of controlled-release oxycodone is smaller than that of controlled-release morphine. ${ }^{4344}$ So consumption of morphine has changed little and has always been lower than that of fentanyl and oxycodone. Consumption of other opioids such as pethidine, codeine and hydromorphone was always low. In one word, the prescription pattern of opioids was generally reasonable.

Our work has some limitations. The data contain no information on compliance with therapy; the term 'consumption' is used for the quantity of drug prescribed but does not relate to how much is actually administered. Second, data on cancer prevalence in Nanjing are not available, so we just analysed the association of cancer incidence and consumption.

\section{CONCLUSION}

In conclusion, during the past few years, the consumption of opioids in Nanjing has increased remarkably, although the level of consumption remains low in comparison with selected worldwide regions. The large increase in the consumption of fentanyl and oxycodone is most likely the main feature of this consumption, whereas the use of morphine is stable. GDP, HDI or cancer incidence, all affected consumption, but were not decisive factors. The Chinese government has initiated steps to emphasise the control of pain and expand pain services, but more needs to be done in the future. However, there has been an opioid crisis in USA and Canada, and expansion of pain services in China needs to be highly regulated.

Contributors XL revised the manuscript. CL drafted the manuscript. HD was responsible for acquisition of data. WF analysed the data and performed the statistical analysis. All authors have read and approved the final manuscript.

Funding Nanjing pharmaceutical association - Changzhou Siyao hospital pharmaceuticals (2018YX004). 
Competing interests None declared.

Patient consent for publication Obtained.

Provenance and peer review Not commissioned; externally peer reviewed.

Data sharing statement The data used and/or analysed during the current study are available from the corresponding author on reasonable request.

Open access This is an open access article distributed in accordance with the Creative Commons Attribution Non Commercial (CC BY-NC 4.0) license, which permits others to distribute, remix, adapt, build upon this work non-commercially, and license their derivative works on different terms, provided the original work is properly cited, appropriate credit is given, any changes made indicated, and the use is non-commercial. See: http://creativecommons.org/licenses/by-nc/4.0/.

\section{REFERENCES}

1. Raffa RB. On subclasses of opioid analgesics. Curr Med Res Opin 2014;30:2579-84.

2. Ghelardini C, Di Cesare Mannelli L, Bianchi E. The pharmacologica basis of opioids. Clin Cases Miner Bone Metab 2015;12:219-21.

3. University of Wisconsin Pain \& Policy Studies Group. Do international model drug control laws provide for drug availability? J Pain Palliat Care Pharmacother 2009;23:145-52.

4. Lohman D, Schleifer R, Amon JJ. Access to pain treatment as a human right. BMC Med 2010;8:8.

5. Seya MJ, Gelders SF, Achara OU, et al. A first comparison between the consumption of and the need for opioid analgesics at country, regional, and global levels. J Pain Palliat Care Pharmacother 2011;25:6-18.

6. Husain SA, Brown MS, Maurer MA. Do national drug control laws ensure the availability of opioids for medical and scientific purposes? Bull World Health Organ 2014;92:108-16.

7. Berterame S, Erthal J, Thomas J, et al. Use of and barriers to access to opioid analgesics: a worldwide, regional, and national study. Lancet 2016;387:1644-56.

8. Fang W, Liu T, Gu Z, et al. Consumption trend and prescription pattern of opioid analgesics in China from 2006 to 2015. Eur J Hosp Pharm:doi: ejhpharm-2017-001460 (Epub ahead of print: 16 Jan 2018)

9. Pan HH, Ho ST, Lu CC, et al. Trends in the consumption of opioid analgesics in Taiwan from 2002 to 2007: a population-based study. $J$ Pain Symptom Manage 2013;45:272-8.

10. Nanjing Statistics Bureau. Statistical yearbook. 2011-2016 http://221.226.86.104/file/nj2004/njtjnj.htm (Accessed 4 Aug 2017).

11. China food and drug administration. The regulations on the administration of anaesthetic drugs and psychotropic. http://samr. cfda.gov.cn/WS01/CL0784/23500.html (Accessed 4 Aug 2017).

12. China food and drug administration. Annual report of drug abuse. 2017;4 http://samr.cfda.gov.cn/WS01/CL0844/175994.html.

13. The World Bank. GDP per capita (current US\$). http://data. worldbank.org/indicator/NY.GDP.PCAP.CD (Accessed 4 Aug 2016).

14. UNDP. Human Development Index and its components. http://hdr. undp.org/en/composite/HDI (Accessed 4 Aug 2016).

15. WHO Collaborating Centre for Drug Statistics Methodology. ATC/ DDD Index. 2017 https://www.whocc.no/atc_ddd_index/ (Accessed 6 Feb 2017).

16. Svendsen K, Mellbye A, Fredheim OMS, et al. 433 Monitoring the opioid consumption: Morphine-equivalent defined daily dose as a supplement to ddd. European Journal of Pain 2009;13(S1):S1 30-S131.

17. Svendsen K, Borchgrevink P, Fredheim O, et al. Choosing the unit of measurement counts: the use of oral morphine equivalents in studies of opioid consumption is a useful addition to defined daily doses. Palliat Med 2011;25:725-32.

18. WHO Collaborating Centre for Drug Statistics Methodology. 19th WHO Model list of essential medicines. http://www.who.int/ medicines/publications/essentialmedicines/EML2015_8-May-15.pdf? $\mathrm{ua}=1 /$ (Accessed 6 Feb 2017)

19. INCB. INCB Technical publications. International narcotics control board, 1995-2015. http://www. incb. org/ incb/ en/ publications/ technical- reports. html (Accessed 24 Oct 2018).

20. Quigley C. Opioids in people with cancer-related pain. BMJ Clin Evid 2008;2008:2408-23.
21. Nickerson JW, Attaran A. Access to controlled medicines for pain relief and anaesthesia in low-income countries. Lancet 2014;383:1802

22. De Lima L, Pastrana T, Radbruch L, et al. Cross-sectional pilot study to monitor the availability, dispensed prices, and affordability of opioids around the globe. J Pain Symptom Manage 2014;48:649-59.

23. Huang Y. Current status of pain management in China: an overview. Eur J Pain 2001;5 Suppl A:67-71.

24. National Health and Family Planning Commission of the People's Republic of China. Establishing "Good Cancer Pain Management Program(GPM program)". http://www.nhfpc.gov.cn/mohyzs/s3586/ 201104/51234.shtml (Accessed 11 Apr 2011).

25. National Health and Family Planning Commission of the People's Republic of China. Hospitals enrolled in "Good Cancer Pain Management Program(GPM program)". In Chinese http://www. nhfpc.gov.cn/mohyzs/s3586/201211/56217.shtml (Accessed 8 Dec 2012)

26. Yang YP, Ma YX, Huang Y, et al. The good pain management (GPM) ward program in China and its impact on Chinese cancer patients: the SYSUCC experience. Chin J Cancer 2014;33:323-9.

27. WHO analgesic pain ladder available online. www.who.int/cancer/ palliative/painladder/en/ (Accessed 06 Sep 2011).

28. Maltoni M, Scarpi E, Modonesi C, et al. A validation study of the WHO analgesic ladder: a two-step vs three-step strategy. Support Care Cancer 2005;13:888-94.

29. Bandieri E, Romero M, Ripamonti Cl, et al. Randomized trial of lowdose morphine versus weak opioids in moderate cancer pain. J Clin Oncol 2016;34:436-42.

30. Caraceni A, Hanks G, Kaasa S, et al. Use of opioid analgesics in the treatment of cancer pain: evidence-based recommendations from the EAPC. Lancet Oncol 2012;13:e58-e68.

31. NCCN. The NCCN Adult Cancer Pain Guideline (Version 1.2015) [EB/ OL]. Fort Washington: NCCN, 2015. (29 Jul 2016).

32. Linge-Dahl L, Vranken $\mathrm{M}$, Juenger $\mathrm{S}$, et al. Identification of challenges to the availability and accessibility of opioids in twelve european countries: conclusions from two ATOME six-country workshops. J Palliat Med 2015;18:1033-9.

33. Kim YC, Ahn JS, Calimag MM, et al. Current practices in cancer pain management in Asia: a survey of patients and physicians across 10 countries. Cancer Med 2015;4:1196-204.

34. Lu CW, Lin CJ, Li JH, et al. Sixteen-year trend of morphine consumption in Taiwan: an international comparison. Chin J Pain 2004;14:1-6.

35. Reddy A, Tayjasanant S, Haider A, et al. The opioid rotation ratio of strong opioids to transdermal fentanyl in cancer patients. Cancer 2016;122:149-56.

36. Radbruch L, Sabatowski R, Loick G, et al. Constipation and the use of laxatives: a comparison between transdermal fentanyl and oral morphine. Palliat Med 2000;14:111-9.

37. Tassinari D, Sartori S, Tamburini E, et al. Transdermal fentanyl as a front-line approach to moderate-severe pain: a meta-analysis of randomized clinical trials. J Palliat Care 2009;25:172-80.

38. Tassinari D, Sartori S, Tamburini E, et al. Adverse effects of transdermal opiates treating moderate-severe cancer pain in comparison to long-acting morphine: a meta-analysis and systematic review of the literature. J Palliat Med 2008;11:492-501.

39. Choi JH, Kang HD, Park JH, et al. The Efficacy of Fentanyl Transdermal Patch as the First-Line Medicine for the Conservative Treatment of Osteoporotic Compression Fracture. Korean $\mathrm{J}$ Neurotrauma 2017;13:130-6.

40. Pietrzyńska T, Pietrzyński Ł. The use of transdermal fentanyl in the treatment of patients suffering from chronic non-cancer pain - case reports]. Pol Merkur Lekarski 2017;43:224-7.

41. Mercadante S, Tirelli W, David F, et al. Morphine versus oxycodone in pancreatic cancer pain: a randomized controlled study. Clin J Pain 2010;26:794-7.

42. Riley J, Branford R, Droney J, et al. Morphine or oxycodone for cancer-related pain? A randomized, open-label, controlled trial. J Pain Symptom Manage 2015;49:161-72.

43. Corli O, Floriani I, Roberto A, et al. Are strong opioids equally effective and safe in the treatment of chronic cancer pain? A multicenter randomized phase IV 'real life' trial on the variability of response to opioids. Ann Oncol 2016;27:1107-15.

44. Schmidt-Hansen M, Bennett MI, Hilgart J. Oxycodone for cancer pain in adult patients. JAMA 2015;314:1282-3. 